\title{
The relationship between ground reaction force components and peak power according to induced fatigue during 16-km walking
}

\author{
Che-Cheong Ryew' ${ }^{1}$, Ae-Ri Lee ${ }^{2}$, Seung-Hyun Hyun ${ }^{1, *}$ \\ 'Department of Kinesiology, College of Natural Science, Jeju National University, Jeju, Korea \\ 2Department of Leisure Sports Majors, Jeju Tourism College, Jeju, Korea
}

The previous reviewed studies on inducement of fatigue through longtime walking were not only very confined, but also not cleared on relationship among variables of fatigue inducement active force, decay rate, and power. This study analyzed relationship between power and component of ground reaction force after fatigue being induced through 16-km walking. The fatigue of adult males and females $(n=16)$ was induced through $16-\mathrm{km}$ walking. Then power, measured for pre and post of fatigue inducement, was evaluated by maximal vertical jump on ground reaction force plate. Variables of vertical jump heights, active force, power, and decay rate showed decreased tendency after fatigue inducement, which followed significant difference $(P<0.05)$ and also positive correlation of $r=0.628\left(R^{2}=39 \%\right)$ of between vertical jump heights and power and $r=0.589\left(R^{2}=34 \%\right)$ of between active force and decay rate respectively. That is, long-time walking for pursuing of exercise rehabilitation, health promotion and leisure activity has been preferred. In the view of this, this study suggested the necessity to understand the relation between fatigue and power to prevent a potential possibility of injury during long-time walking.

Keywords: Walking, Fatigue, Vertical jump, Power, Correlation

\section{INTRODUCTION}

Gait is the most common activity which human performs, and parameters (e.g., velocity, step length, and step frequency) of it, have been considered to be the important factors causing falling injury (Oberg et al., 1993). Also fatigue affecting negatively on walking ability and imbalance of center of gravity (COG) has been indicated as main dangerous factor (Parijat and Lockhart, 2008).

It is necessary to be permitted a more cyclic correction against a swaying motion of COG and therefore more supporting time of bi-leg occurring when fatigue was cumulated during human locomotion (Nagano et al., 2014). Also fatigue has been pointed as one of internal factor contributing to slippery and falling injury, and then may induce deterioration of signaling quality transferring from sensory input, slippery and falling injury (Parijat and Lockhart, 2008).
Amplitude of shock wave by accelerator at heel stride during running using treadmill was detected on between shank and sacrum (Mizrahi et al., 2000; Voloshin et al., 1998). That is, fatigue in case of repetitive contraction of muscle prevented a force exertion or response on signal of the same contraction (Asmussen, 1993), and therefore suggested that countermeasurement capability of muscular-skeletal system attenuating a shock wave was weakened.

Thus fatigue cumulated during locomotion has close relation between motor ability and reduction of power. Thus it is needless to say that necessity of power strengthening during physical activity, furthermore those who participate in various physical activities of athlete leader, player etc. should allocate their much portion of time for improvement of muscle strength. Particularly, when foot was stumbled and external force was exerted on body during locomotion, it is important to reduce angular momentum by positioning at more front position in order to generate forward
${ }^{*}$ Corresponding author: Seung-Hyun Hyun (iD https://orcid.org/0000-0001-6348-6413 Department of Kinesiology, College of Natural Science, Jeju National University, 102 Jejudaehak-ro, Jeju 63243, Korea

E-mail: hshyun0306@jejunu.ac.kr

Received: July 7, 2019 / Accepted: August 22, 2019
This is an Open Access article distributed under the terms of the Creative Commons Attribution Non-Commercial License (http://creativecommons.org/licenses/by-nc/4.0/) which permits unrestricted non-commercial use, distribution, and reproduction in any medium, provided the original work is properly cited. 
power (Pavol et al., 2001). Power during locomotion plays a important role on normal locomotion and control of body, because functional activity of which is possible when muscle can generate power (Perry et al., 2007).

Many efforts investigating relation of between walking ability and fatigue has been performed, of which method of fatigue inducement was recruited with cycling test or CYBEX system (Abbiss et al., 2010; Barbieri et al., 2013; Lepers et al., 2002; Marchetti et al., 2013; Vanhatalo et al., 2007; Yaggie and McGregor, 2002). But, these methods had difficulty in inducement of effect of muscle fatigue of whole body like balancing controllability and positioning sense of articular.

Fatigue induce method based on walking had been suggested by long-time walking at preferred velocity during from $20 \mathrm{~min}$ to $3 \mathrm{hr}$ (Yoshino et al., 2004). Recently exercise participants preferring physical activities like long-time trekking, climbing, and walking for purpose of weight reduction, exercise rehabilitation, health and wellbeing etc. had been increased (Campaña and Costa, 2017; Kim, 2018; Ryew and Hyun, 2016). Like these, it is necessary to induce fatigue through long-time walking, but relation of these variables related with power is not yet clear.

In conclusion, the aim of the study was to investigate quantitative effect on variables of power (peak vertical jump heights and peak power) and ground reaction force components (active force and decay rate) on fatigue occurred through 16-km locomotion.

\section{MATERIALS AND METHODS}

\section{Subject}

Healthful adult male and female $(\mathrm{n}=16)$ (male, 4; female, 12; mean age, $21.57 \pm 1.08$ years; mean heights, $167.12 \pm 10.35 \mathrm{~cm}$; mean weights, $62.16 \pm 11.73 \mathrm{~kg}$ ) participated in the experiment. All participants agreed voluntarily on the study's aim and range were proved to be normal for long-time walking.

\section{Experimental procedure}

Pre-post power of cumulated fatigue through 16-km walking was replaced with maximal vertical jump (Lara et al., 2006), and maximal vertical jump was performed on force platform (AMTI-OR-7, Advanced Mechanical Technology Inc., Watertown, MA, USA) and sampling rate was set at 1,000 $\mathrm{Hz}$ (Gain: $4 \mathrm{k}$, Voltage: 5 V) for $5 \mathrm{sec}$.

Each participants, when premeasurement was completed for vertical jump, jumped immediately in accordance with extension of each joint after a series of motion of maximal flexion-lowering of COG-pre-downward motion of knee and hip joint after starting from elect position (Linthorne, 2001). When other problems (data transfer error, deviation of ground reaction force range, etc.) was occurred, maximal 5 times repetitive trial was allowed for experimental reliability with intermediate rest time. After premeasurement, 16-km walking was performed on the field of outdoor road and wild field with researcher, and was maintained mean velocity of $4.5-5 \mathrm{~km}$ per hr. Mean velocity was calculated by total distance per elapsed time, and other hand luggage was not more than $5 \%$ of total body weight. Normal participants who can perform the post jump measurement after long-time walking entered experiment laboratory within $30 \mathrm{~min}$ and performed post measurement.

\section{Definition of analysis phase}

All vertical jump heights were determined by the flight time from the contact ground reaction force according to the formula of (Cronin and Hansen, 2005; Young, 1995).

$$
\text { Jump heights }(\mathrm{cm})=g t^{2} / 8
$$

where, $g=$ acceleration due to gravity $\left(9.81 \mathrm{~m} / \mathrm{sec}^{2}\right), t=$ flight time of the jump (sec)

The power was estimated using the equations developed by (Sayers et al., 1999).

Power $(\mathrm{W})=(60.7) \times($ jump height, $\mathrm{cm})+45.3 \times$ body mass $-2,055$

Table 1. Change of power and ground reaction force components

\begin{tabular}{|c|c|c|c|c|c|}
\hline \multirow{2}{*}{ Section } & \multicolumn{2}{|c|}{ Maximum vertical jump test } & \multirow{2}{*}{$\%$} & \multirow{2}{*}{$t$} & \multirow{2}{*}{$P$-value } \\
\hline & Pretest & Posttest & & & \\
\hline Vertical jump heights (cm) & $33.78 \pm 7.26$ & $26.95 \pm 4.26$ & -17.63 & 4.276 & $0.001^{* * *}$ \\
\hline Active force (N/BW) & $2.42 \pm 0.36$ & $1.93 \pm 0.59$ & -18.17 & 2.600 & $0.020^{*}$ \\
\hline Power (W) & $2,585.57 \pm 732.09$ & $2,215.97 \pm 762.82$ & -15.97 & 5.377 & $0.001^{* * *}$ \\
\hline Decay rate (N/BW/sec) & $-32.35 \pm 7.85$ & $-21.68 \pm 8.42$ & -29.80 & -3.737 & $0.002^{* *}$ \\
\hline
\end{tabular}

Values are presented as mean \pm standard deviation.

$\%$, change ratio; BW, body weight.

${ }^{*} P<0.05$. ${ }^{* *} P<0.01$. ${ }^{* *} P<0.001$. 
The formula adopted because difference of sex on accuracy of power estimates does not effect, and then correlation between ground reaction force and switch mat was $r=0.99$ (Hertogh and Hue, 2002; Sayers et al., 1999).

Active force means maximal point of vertical ground reaction force before maximal vertical jump, which is a normalized value $(\mathrm{N} / \mathrm{BW})$ of newton $(\mathrm{N})$ value per body weight $(\mathrm{BW}) \times$ acceleration of gravity. Load reduction ratio (\%) means value $(\mathrm{N} / \mathrm{BW} / \mathrm{sec})$ of active force divided with elapsed time to point releasing from take-off on ground.

\section{Analysis and process of data}

Significant test to pre-post fatigue cumulated during $16-\mathrm{km}$ walking was performed paired $t$-test with PASW ver. 21.0 (IBM.,
Chicago, IL, USA). Pearson product-moment correlation with change ratio (\%) of pre-post measurement and linear regression for pattern prediction among independent variable were processed respectively at $\alpha<0.05$ level.

Table 2. Correlation relative between power and ground reaction force components during 16-km walking $(r)$

\begin{tabular}{lcccc}
\hline Section & $\begin{array}{c}\text { Vertical jump } \\
\text { heights }\end{array}$ & Active force & Power & Decay rate \\
\hline Vertical jump heights & 1 & 0.341 & $0.628^{* *}$ & 0.331 \\
Active force & & 1 & 0.268 & $0.589^{*}$ \\
Power & & & 1 & 0.160 \\
Decay rate & & & & 1 \\
\hline
\end{tabular}

${ }^{*} P<0.05 .{ }^{* *} P<0.01$.
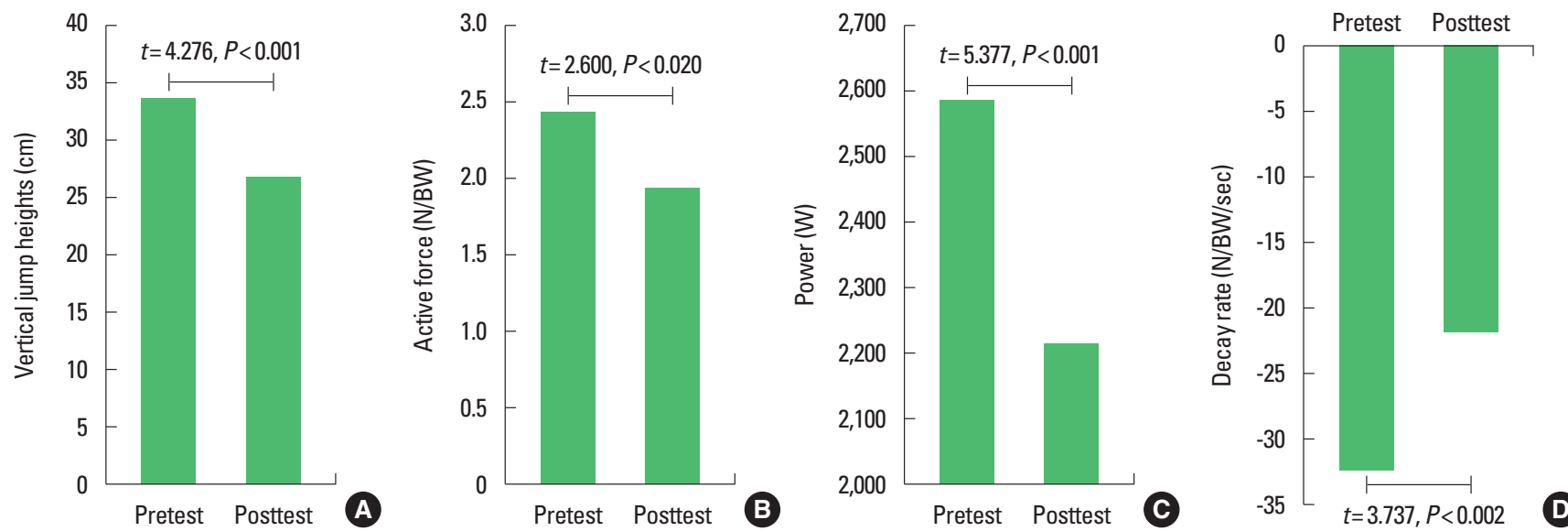

Fig. 1. Change of power and ground reaction force components. (A) Vertical jump heights. (B) Active force (N/BW). (C) Power (W). (D) Decay rate (N/BW/sec). BW, body weight.
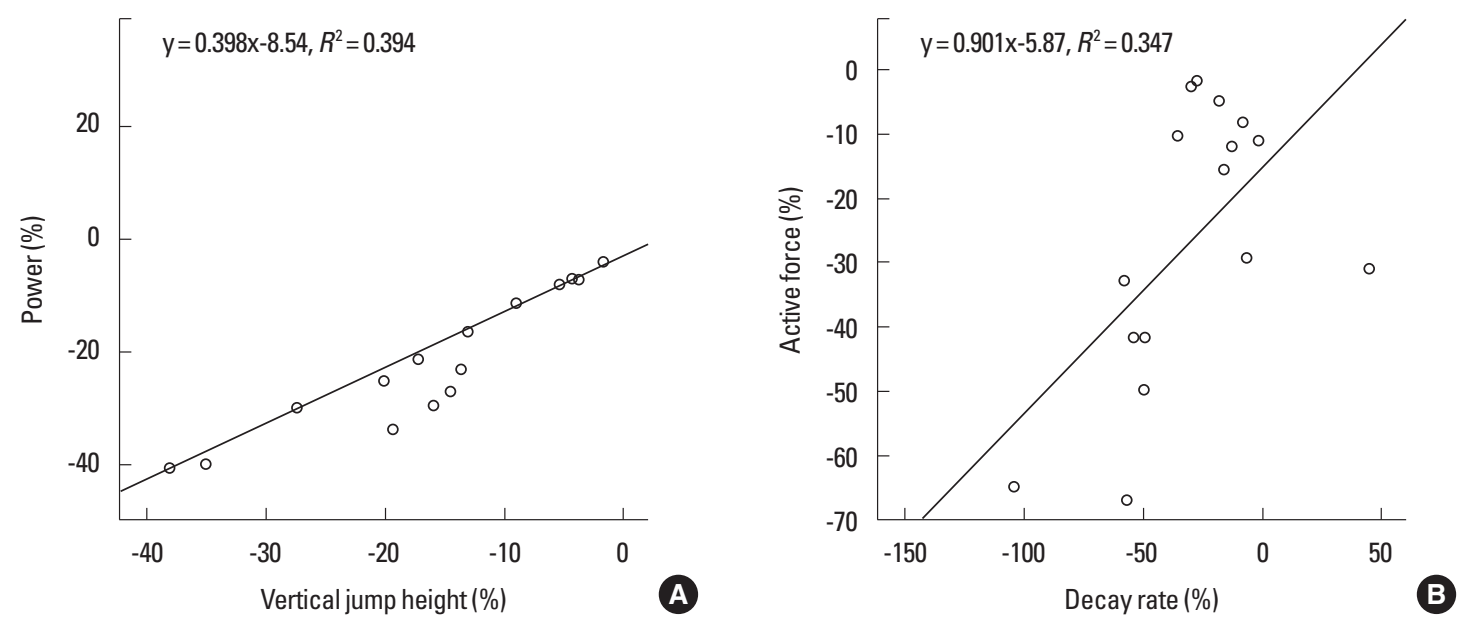

Fig. 2. Linear regression analysis. (A) Correlation of $r=0.628$ between vertical jump height and power. (B) Correlation of $r=0.589$ between decay rate and active force. 


\section{RESULTS}

In Table 1 and Fig. 1, fatigue cumulated due to 16-km walking reduced all variables of vertical jump heights (Fig. $1 \mathrm{~A}, P<0.001$ ), active force (Fig. 1B, $P<0.020$ ), power (Fig. 1C, $P<0.001$ ), and decay rate (Fig. 1D, $P<0.002$ ), which followed significant difference.

In Table 2 and Fig. 2, change ratio (\%) of variables following pre-post fatigue showed high positive correlation of $r=0.628$ $\left(y=0.398 \times-8.54, R^{2}=0.394\right)$ between vertical jump height and power and also showed similar positive correlation of $r=0.589$ $\left(y=0.901 \times-5.87, R^{2}=0.347\right)$ between decay rate and active force.

\section{DISCUSSION}

Walking exercise relied on one's muscular strength (Schweizer et al., 2014), and importance of muscular strength relative to walking velocities was confirmed in a view of one's preferred convenient velocity and maximal velocity (Bohannon, 1997; Schweizer et al., 2014). But fatigue was felt when maximal force and power decreased (Enoka and Duchateau, 2008). Until now, various fatigue inducement method was recruited to investigate relation between walking and fatigue, but the case which adopted a functional fatigue method (walking) was very rare. This study tested effect on the change ratio $(\%)$ of variables related with fatigue following fatigue inducement cumulated through $16-\mathrm{km}$ walking.

Variables of vertical jump heights, power, active force, and decay rate after fatigue inducement than before participation of experiment showed decreasing tendency, which satisfied 1st assumption. Vertical jump test has been accepted as accurate and reliable tool which can evaluate a muscular strength and power of lower limb (Lara et al., 2006), and then performance of ballistic exercise was depended on maximal power which can be exerted in condition of mechanical condition given to muscular system (Bobbert, 2012). Therefore, this study showed characteristics which fatigue cumulated through long-time walking may contribute negatively to the height of vertical jump and reduction of power.

Particularly in this study, because vertical jump test was performed on ground reaction force plate, it should be concentrated on the change ratio (\%) of active force and decay rate. Active force is maximal vertical force on action and reaction force occurring in prephase before vertical jump. Velocity taking off from ground reaction force after occurrence of the force can be explained as decay rate (Ryew and Hyun, 2018).
In many previous studies, when considering the fact that height of maximal vertical jump was regarded as valid scale determining a maximal power (Baker et al., 2001; Lara et al., 2006; Samozino et al., 2008), fatigue inducement through long-time walking in this study resulted in similar reduction tendency of between vertical jump height and power $\left(R^{2}=39 \%\right)$. Also positive correlation between active force and decay rate was proved that reduction of force acting downward ground before maximal vertical jump influenced on reduction of velocity of vertical take-off $\left(R^{2}=34 \%\right)$.

Such long-time exercises as running and cross-country ski has been focused on investigating an effect on neuromuscular function (Davies and Thompson, 1986; Nicol et al., 1991). Of which stretchshortening cycles during marathon running effected on production of muscle force due to reduction of nerve injection on muscle and lowering efficiency of contraction mechanism. Thus physiological fatigue on efficiency and stimulus of muscle mechanism may disturb regular pattern of not only running but also even gait (Parijat and Lockhart, 2008).

Walking reduced possibility of cardiovascular diseases, moreover, it helps to prevent obesity (Campaña and Costa, 2017; Kim, 2018; Ryew and Hyun, 2016). But when gait continued for long time, it may not be maintained a normal gait mechanism and controllability under condition of external force (collision), foot obstacle, sloping load and slipping etc. Thus it is necessary for individuals for exercise rehabilitation, aerobic exercise and leisure exercise to understand one's level of fatigue threshold. On the basis of result of the study, further study should be performed which can develop various tool and method to predict an individual's fatigue level easily

\section{CONFLICT OF INTEREST}

No potential conflict of interest relevant to this article was reported.

\section{ACKNOWLEDGMENTS}

This work was supported by the 2019 education, research and student guidance grant funded by Jeju National University.

\section{REFERENCES}

\footnotetext{
Abbiss CR, Burnett A, Nosaka K, Green JP, Foster JK, Laursen PB. Effect of hot versus cold climates on power output, muscle activation, and perceived fatigue during a dynamic $100-\mathrm{km}$ cycling trial. J Sports Sci
} 


\section{0;28:117-125.}

Asmussen E. Muscle fatigue. Med Sci Sports Exerc 1993;25:412-420.

Baker D, Nance S, Moore M. The load that maximizes the average mechanical power output during jump squats in power-trained athletes. J Strength Cond Res 2001;15:92-97.

Barbieri FA, dos Santos PC, Vitório R, van Dieën JH, Gobbi LT. Effect of muscle fatigue and physical activity level in motor control of the gait of young adults. Gait Posture 2013;38:702-707.

Bobbert MF. Why is the force-velocity relationship in leg press tasks quasi-linear rather than hyperbolic? J Appl Physiol (1985) 2012;112:19751983.

Bohannon RW. Comfortable and maximum walking speed of adults aged 20-79 years: reference values and determinants. Age Ageing 1997;26: 15-19.

Campaña CT, Costa PB. Effects of walking with hand-held weights on energy expenditure and excess postexercise oxygen consumption. J Exerc Rehabil 2017;13:641-646.

Cronin JB, Hansen KT. Strength and power predictors of sports speed. J Strength Cond Res 2005;19:349-357.

Davies CT, Thompson MW. Physiological responses to prolonged exercise in ultramarathon athletes. J Appl Physiol (1985) 1986;61:611-617.

Enoka RM, Duchateau J. Muscle fatigue: what, why and how it influences muscle function. J Physiol 2008;586:11-23.

Hertogh C, Hue O. Jump evaluation of elite volleyball players using two methods: jump power equations and force platform. J Sports Med Phys Fitness 2002;42:300-303.

Kim DY. Effects of exercise using a mobile device on cardiopulmonary function, metabolic risk factors, and self-efficacy in obese women. J Exerc Rehabil 2018;14:829-834.

Lara A, Alegre LM, Abián J, Jiménez L, Ureña A, Aguado X. The selection of a method for estimating power output from jump performance. J Hum Mov Stud 2006;50:399-410.

Lepers R, Maffiuletti NA, Rochette L, Brugniaux J, Millet GY. Neuromuscular fatigue during a long-duration cycling exercise. J Appl Physiol (1985) 2002;92:1487-1493.

Linthorne NP. Analysis of standing vertical jumps using a force platform. Am J Phys 2001;69:1198-1204.

Marchetti PH, Orselli MI, Duarte M. The effects of uni- and bilateral fatigue on postural and power tasks. J Appl Biomech 2013;29:44-48.

Mizrahi J, Verbitsky O, Isakov E. Fatigue-related loading imbalance on the shank in running: a possible factor in stress fractures. Ann Biomed Eng 2000;28:463-469.

Nagano H, James L, Sparrow WA, Begg RK. Effects of walking-induced fatigue on gait function and tripping risks in older adults. J Neuroeng
Rehabil 2014;11:155.

Nicol C, Komi PV, Marconnet P. Fatigue effects of marathon running on neuromuscular performance: I. Changes in muscle force and stiffness characteristics. Scan J Med Sci Sports 1991;1:10-17.

Oberg T, Karsznia A, Oberg K. Basic gait parameters: reference data for normal subjects, 10-79 years of age. J Rehabil Res Dev 1993;30:210-223.

Parijat P, Lockhart TE. Effects of lower extremity muscle fatigue on the outcomes of slip-induced falls. Ergonomics 2008;51:1873-1884.

Pavol MJ, Owings TM, Foley KT, Grabiner MD. Mechanisms leading to a fall from an induced trip in healthy older adults. J Gerontol A Biol Sci Med Sci 2001;56:M428-437.

Perry MC, Carville SF, Smith IC, Rutherford OM, Newham DJ. Strength, power output and symmetry of leg muscles: effect of age and history of falling. Eur J Appl Physiol 2007;100:553-561.

Ryew CC, Hyun SH. Effect of the kinetic variables and postural stability between bilateral in lower limbs by the Oreum trekking exercise: asymmetric index. J Exerc Rehabil 2016;12:368-372.

Ryew CC, Hyun SH. The contribution analysis of knee compression bandage and arm swing control on maximum horizontal distance in standing long jump. J Exerc Rehabil 2018;14:239-243.

Samozino P, Morin JB, Hintzy F, Belli A. A simple method for measuring force, velocity and power output during squat jump. J Biomech 2008; 41:2940-2945.

Sayers SP, Harackiewicz DV, Harman EA, Frykman PN, Rosenstein MT. Cross-validation of three jump power equations. Med Sci Sports Exerc 1999;31:572-577.

Schweizer K, Romkes J, Coslovsky M, Brunner R. The influence of muscle strength on the gait profile score (GPS) across different patients. Gait Posture 2014;39:80-85.

Vanhatalo A, Doust JH, Burnley M. Determination of critical power using a 3-min all-out cycling test. Med Sci Sports Exerc 2007;39:548-555.

Voloshin AS, Mizrahi J, Verbitsky O, Isakov E. Dynamic loading on the human musculoskeletal system -- effect of fatigue. Clin Biomech (Bristol, Avon) 1998;13:515-520.

Yaggie JA, McGregor SJ. Effects of isokinetic ankle fatigue on the maintenance of balance and postural limits. Arch Phys Med Rehabil 2002;83: 224-228

Yoshino K, Motoshige T, Araki T, Matsuoka K. Effect of prolonged freewalking fatigue on gait and physiological rhythm. J Biomech 2004;37: 1271-1280.

Young W. A simple method for evaluating the strength qualities of the leg extensor muscles and jumping abilities. Strength Cond Coach 1995; $2: 5-8$. 